
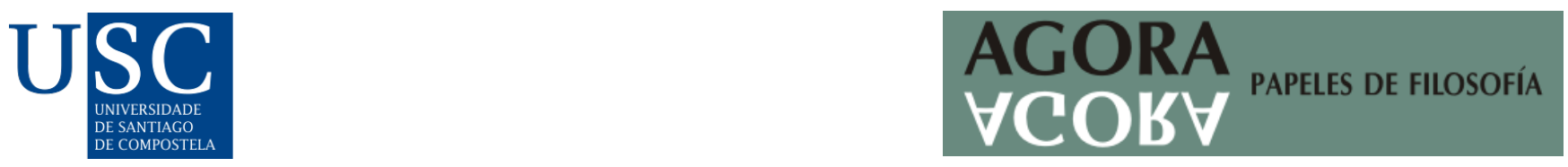

Agora. Papeles de Filosofía, 41(1), 2022. ISSN-e: 2174-3347

https://doi.org/10.15304/agora.41.1.7993

Recensiones

\title{
MERCIER, Hugo; SPERBER, Dan: The Enigma of Reason. A New Theory of Human Understanding, Penguin Books, London, 2018, 396p.
}

\author{
Martín Pereira Fariña
}

Recibido: 07/10/2021; Aceptado: 08/10/2021

La pregunta sobre qué es y cómo funciona la racionalidad humana ha sido objeto de reflexión filosófica desde la Antigua Grecia, cuando se definió al ser humano como un "ser racional" y un "animal político". A partir de este momento, la racionalidad se constituye como una especie de "superpoder" exclusivo de la especie humana que nos permite ser más "knowledgeable and wise" (p. 1). A pesar de esto, nuestro pensamiento racional no está exento de defectos y sesgos, ampliamente estudiados por la psicología del razonamiento. ¿Cómo se puede casar esta aparente contracción?

Esa cuestión el desencadenante que guía la indagación sobre la racionalidad humana expuesta por H. Mercier y D. Sperber. La tesis central del libro define la racionalidad como un componente evolutivo más de nuestra mente como animales humanos, adaptada a la vida en sociedad (nuestro "nicho ecológico"), y cuyos "defectos" son simplemente características. A través de 18 capítulos, organizados en cinco grandes bloques, los autores desarrollan esta tesis asentándola en dos pilares básicos: i) un análisis crítico de la teoría tradicional sobre la racionalidad humana; y, ii) elaborar una nueva aproximación que explique la funcionalidad de nuestras supuestas deficiencias.

El bloque I, de carácter introductorio, resume el modelo de la mente dual ("pensar rápido, pensar despacio") propuesto por D. Kahneman y A. Tversky, uno de los más extendidos. Nuestro sistema cognitivo está compuesto por dos sistemas: el Sistema 1, ágil, rápido, inconsciente, contextual y no verbal, con el que tomamos las decisiones intuitivas; y el Sistema 2, perezoso, lento, consciente, descontextualizado y verbal, con el que tomamos las decisiones reflexivas. Por lo tanto, cuando queremos mejorar nuestro conocimiento y tomar mejores decisiones usamos el Sistema 2; es decir, razonamos. Sin embargo, esta propuesta genera un "Doble Enigma” (p. 1): i) ¿por qué sólo los humanos tenemos esa facultad cognitiva de razonar?; ii) ¿por qué cometemos tantos errores al razonar?

El bloque II, compuesto por cuatro capítulos, aborda esas dos preguntas. Toma como punto de partida la distinción entre "inferir" y "razonar". Inferir consiste en "extraction of new information from information already available, whatever the process" (p. 53) y la llevan a cabo todos los animales. Razonar denota un tipo de inferencia basado en "attending to reasons" (p. 53) y es característica de los seres humanos. Inferimos empleando distintos mecanismos (entre los que destaca la intuición), cada uno de los cuales constituye un "módulo" (cap. 4). Razonamos cuando necesitamos aportar razones para explicar o justificar nueva información ante otros congéneres. 
Por lo tanto, nuestra mente no funciona como un sistema dual sino como una articulación dinámica de módulos sensible al contexto en el que estamos.

En su operativa, las inferencias necesitan dos elementos fundamentales: representaciones (información codificada acerca del estado del mundo) y procesos (extraer nueva información fiable a partir de la información disponible). El factor diferencial de la mente humana con respecto de la mente de otros animales es su capacidad de realizar representaciones de representaciones; es decir, metarepresentaciones (cap. 6). Esta no sólo nos permite caracterizar o atribuir propiedades a nuestros propios estados mentales sino también atribuir estados mentales a otros sujetos (según los autores, no tenemos más éxito haciendo lo primero que lo segundo). Aunque no se menciona en el texto, esta capacidad de meta-representación infinita es una forma de recursión, algo que M. Corballis también postula como singular y exclusivo de los seres humanos.

Así pues, el bloque II presenta los dos pilares básicos sobre los que se asientan las tesis centrales del libro: el razonar es un módulo meta-representacional con el que llevamos a cabo cierto tipo de inferencias, y una facultad adaptativa de los seres humanos a la vida en sociedad.

Los bloques III y IV comprenden las contribuciones principales y más novedosas del libro. El bloque III, compuesto por cuatro capítulos, indaga en el razonar desde una perspectiva evolutiva a través de dos cuestiones fundamentales: i) ¿para qué nos sirve la razón?; y, ii) ¿cómo funciona la razón? Con respecto a la primera cuestión, es imprescindible concebir al ser humano como un ser social y lingüístico, siendo la comunicación y la cooperación sus pilares fundamentales. Esto implica una concepción del razonar esencialmente argumentativa, bien elaborando argumentos propios bien evaluando los argumentos que se nos presentan. Cuando los elaboramos nosotros, bien sea de forma retrospectiva (mediante explicaciones o mediante justificaciones) o prospectiva (bien indagando o bien argumentando) (p. 129), tendemos a seleccionar aquellas razones que justifican nuestra conclusión (el usualmente llamado confirmation bias o sesgo de confirmación que los autores renombran como myside bias o "sesgo de mi postura") y desdeñar aquellas que la invaliden. "Tener razón" nos sirve para mantener y mejorar nuestra "reputación social" (p. 143). Cuando evaluamos argumentos, operamos justo del modo contrario, identificamos mucho mejor las debilidades del argumento presentado que sus fortalezas mediante nuestra "vigilancia epistémica" (p. 191 y ss), pues nos ayuda a evitar los engaños. En resumen, "reasons are social constructs and for social consumption" (p. 127).

El bloque IV evalúa los límites de la razón, hasta dónde puede y no puede llegar. ¿Es infalible nuestra razón? Claramente no. Son conocidas diversas formas de explotar esas debilidades (cfr. con The Psychology of Persuasion de R. Cialdini). ¿Por qué no es infalible? Según apuntan Sperber y Mercier, por una cuestión de "economía": la división entre nuestras habilidades para elaborar y evaluar argumentos es una forma de división de la labor cognitiva (p. 221). Razonar bien, buscando las debilidades de nuestros argumentos, requiere un gran consumo de energía. Si lo hacemos dialógicamente, serán nuestros interlocutores los que asuman esa tarea, reduciendo así nuestra carga cognitiva sin penalizar la fortaleza de nuestros argumentos. Sin embargo, ¿qué acontece cuando argumentamos sin discusión? Caemos en lo que los autores denominan "The Dark Side of Reason" (cap. 13). Si nuestras tesis o afirmaciones no se discuten, sino que sólo se reafirman sin comentarios críticos, llevamos al extremo nuestro sesgo de confirmación. Es realmente interesante el caso del Premio Nobel en química Linus Pauling, quien se reafirmaba cada vez más en el poder de la Vitamina C para curar todo tipo de enfermedades en contra de la evidencia científica disponible. Incluso una argumentación realizada en pequeños grupos sin discusión crítica, aun siendo dialógica, puede comprometer nuestra capacidad para "anticipar desacuerdos" (p. 249) 
y provocar los efectos contrarios: polarización, exceso de confianza y perseverancia en nuestras creencias o prejuicios. A modo de ejemplo, pensemos en como los algoritmos de Inteligencia Artificial determinan el contenido que consumimos en Internet. Estos explotan precisamente esa característica de nuestra razón para mantenernos siempre conectados a aquello que queremos ver o escuchar, provocando la minimización de la discusión en lugar de fomentarla.

Otro de los peligros de nuestra razón que "los seres humanos somos máquinas de racionalizar" (p. 253) no sólo máquinas de razonar. Cuando partimos de una intuición fuerte y tenemos que justificar esa decisión, buscamos razones que apoyen esa decisión, independientemente de que esas razones tengan o no una relación de causalidad con nuestra tesis.

El último gran bloque de este libro, el V, analiza la razón y el razonar desde una perspectiva más amplia, global y pragmática. Aborda dos cuestiones fundamentales, la primera versa sobre cómo la psicología ha centrado sus investigaciones casi exclusivamente en los países democráticos occidentales e industrializados (los llamados WEIRD, Western, Educated, Industrialized, Rich and Democratic). Esto puede limitar la generalización de sus conclusiones a otros países, ¿cómo de dependiente es el razonar la cultura? Sus primeros resultados apuntan que estos rasgos de la razón se pueden identificar universalmente, pero se requiere más investigación. La otra gran cuestión abordada es el razonar sobre aspectos morales y políticos. Concluyen que la deliberación (diálogo crítico en una comunidad) y el diálogo racional (expresado en un modo similar a la noción de pragma-dialéctica de F. Van Eemeren) nos sirven para mejorar nuestras decisiones como sociedad. Los autores concluyen con un alegato final a favor de la razón. Debemos de dejar de considerarla como un superpoder, y verla como otra facultad más, que tiene que ser entendida en su contexto (social y evolutivo) para no ser víctimas de sus limitaciones y defectos y beneficiarnos de sus virtudes.

Este libro constituye una de las presentaciones más originales y estimulantes tanto para las ciencias cognitivas como para la teoría de la argumentación de los últimos años. No sólo está escrito con gran claridad e ilustrado con un gran número de ejemplos, sino que muestra cómo ciertos experimentos clásicos de la psicología, realizados con mínimos cambios, ofrecen unos resultados completamente distintos. Este libro sitúa la comunicación y la vida social en el centro de nuestra actividad razonadora y argumentativa, ofreciendo un nuevo sustento para todas las disciplinas relacionas con el estudio de esta dimensión del lenguaje, como la teoría de la argumentación, el análisis del discurso, la filosofía del lenguaje o la filosofía de la mente. Una obra de imprescindible lectura para cualquier investigador interesado en el tema. 